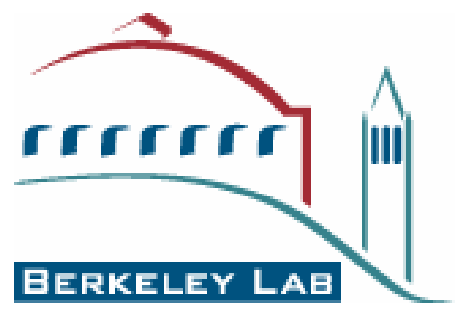

\title{
DATA MONITORING AND ANALYSIS PROGRAM MANUAL
}

LBNL/PUB-5519 (3), Rev. 0

Effective Date:

Orlando Lawrence Berkeley National Laboratory 


\section{REVISION HISTORY}

\begin{tabular}{|l|l|l|}
\hline Revision & Date & Revision Description \\
\hline & & \\
\hline & & \\
\hline & & \\
\hline
\end{tabular}




\section{TABLE OF CONTENTS}

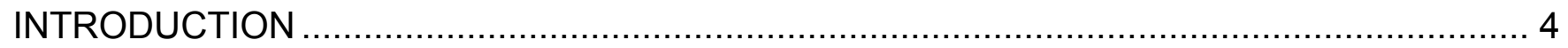

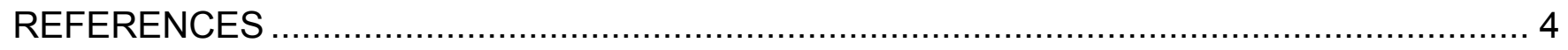

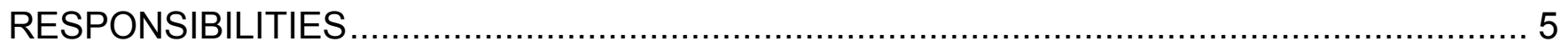

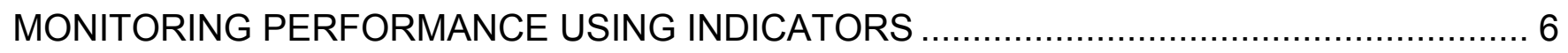

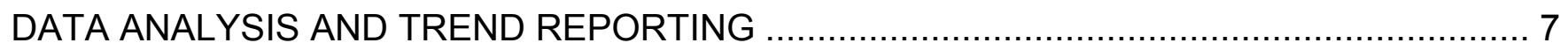

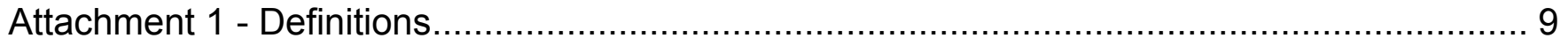

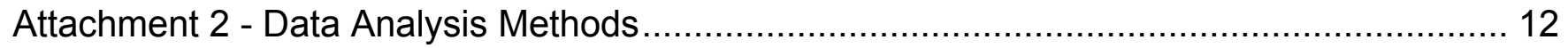

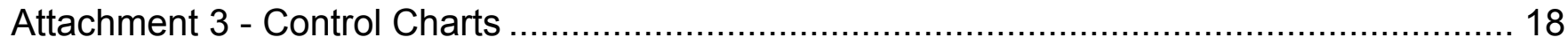

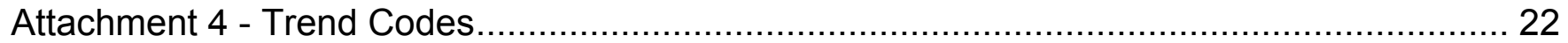




\subsection{INTRODUCTION}

This procedure provides guidelines and techniques for analyzing and trending data using statistical methods for Lawrence Berkeley National Laboratory (LBNL). This procedure outlines the steps used in data analysis and trending. It includes guidelines for performing data analysis and for monitoring (or controlling) processes using performance indicators.

This procedure is used when trending and analyzing item characteristics and reliability, process implementation, and other quality-related information to identify items, services, activities, and processes needing improvement, in accordance with 10 CFR Part 830, Subpart A, U.S. Department of Energy (DOE) Order 414.1C, and University of California (UC) Assurance Plan for LBNL.

Trend codes, outlined in Attachment 4, are assigned to issues at the time of initiation and entry into the Corrective Action Tracking System (CATS) database in accordance with LBNL/PUB5519 (1), Issues Management Program Manual.

Throughout this procedure, the term performance is used to encompass all aspects of performance including quality, timeliness, efficiency, effectiveness, and reliability. Data analysis tools are appropriate whenever quantitative information describing the performance of an item, service, or process can be obtained.

Performance of this procedure produces the following records, which are maintained in accordance with the Regulations and Procedures Manual:

- Periodic Trend Report

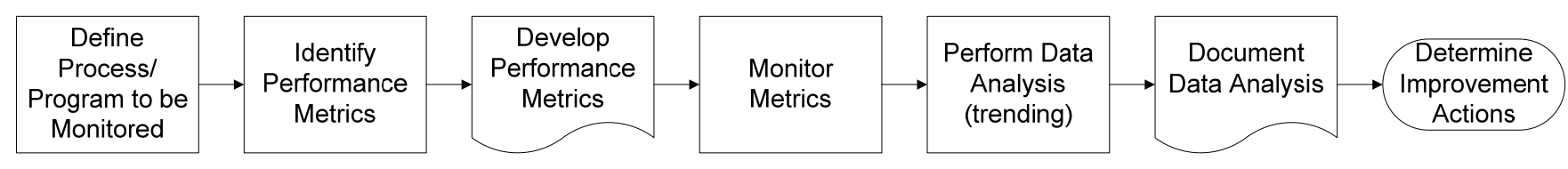

\subsection{REFERENCES}

Baseline Documents

- 10 CFR Part 830, Subpart A, "Quality Assurance Requirements"

- DOE Order 414.1C, Quality Assurance

- DOE O 5480.19, Conduct of Operations Requirements for DOE Facilities

- UC Assurance Plan for LBNL

- LBNL Pub-3000, Health and Safety Manual 
- Manual for PAAA Program Communications, Oversight and Reporting Processes REFERENCED DOCUMENTS

- LBNL/PUB-5519 (1), Issues Management Program Manual

- LBNL/PUB-5519 (2), Root Cause Analysis Program Manual

\subsection{RESPONSIBILITIES}

\subsection{Analyst}

3.1.1 Identifies data sources and collection frequencies

3.1.2 Identifies chart and report formats

3.1.3 Analyzes indicator data

3.1.4 Identifies trends and other changes

3.1.5 Obtains program technical authority (e.g. subject matter expert (SME)) concurrence with analysis as needed

3.1.6 Assesses implementation of this procedure

3.1.7 Documents and processes identified adverse trends

\subsubsection{Prepares reports}

\subsection{Management}

3.2.1 Ensures that data analysis and trending activities are performed per this procedure

3.2.2 Identifies the needs for data analysis and/or trending in order to identify items, services, and processes needing improvement

3.2.3 Ensures that analysts who develop indicators, calculate control limits, perform statistical analyses, and develop systems and methodologies for performing data analysis and trending possess the necessary competencies

3.2.4 Approves trending and analysis methodologies

3.2.5 Ensures that sufficient analyst and SME resources are allocated to perform trending and data analysis 
3.2.6 Ensures distribution of performance trend analysis reports to affected functional or program areas and to applicable oversight organizations

3.2.7 Ensure that SMEs provide input to analyses and reports as necessary

3.2.8 Ensures that adverse trends identified through trending and data analysis are documented and processed as deficiencies in accordance with LBNL/PUB-5519 (1).

3.2.9 Evaluates performance metrics and trend reports to identify adverse root causes

3.2.10 Ensures that the results of the evaluation are reported to the organization responsible for corrective action

\subsection{SME}

3.3.1 Provides technical input to assist in the evaluation of indicated trends and other changes as necessary.

\subsection{MONITORING PERFORMANCE USING INDICATORS}

\section{NOTE}

Data analysis refers to a one time analysis or a series of infrequent and irregularly occurring analyses. Data analysis is performed per Section 5.0. Regularly scheduled, recurring analyses are termed "monitoring" and are performed per this section.

Analyst

4.1 Identify needs for monitoring performance in specific programs, products, or processes.

4.2 Identify the purpose for assessing the performance such as:

- Monitor for changes in performance

- Maintain performance within specified limits

- Monitor the effects of improvement efforts on performance

4.3 Identify targets, goals, objectives, or other expectations for maintaining or changing performance.

4.4 Identify monitoring and reporting frequencies.

4.5 Develop the performance indicator(s), and collect and analyze the appropriate data. 
4.6 Identify the specific item characteristic(s) or process/quality-related information that is to be monitored or controlled.

4.7 Define and document the performance indicator.

4.8 Collect and analyze the data.

4.9 Identify the source(s) of the data.

4.10 Consult with appropriate SME for background information on identified variations.

4.11 Report findings and observations to management.

Management

4.12 Review the documentation prior to issuance.

\section{NOTE}

Appropriate actions may include gathering and analyzing additional data to determine the importance and impacts of reported findings and observations or initiating corrective action through the applicable corrective action process.

4.13 Ensure that appropriate actions are taken based on the findings and observations.

4.14 Initiate process improvement studies and initiatives as applicable.

4.15 Modify/approve changes to goals, targets, and/or control limits as applicable.

\subsection{DATA ANALYSIS AND TREND REPORTING}

Analyst

5.1 Identify needs for data analysis in specific programs, products, or processes.

5.2 Identify the purpose for assessing the performance. This could be to:

- Determine if a change has occurred (one-time analysis).

- Identify the causes/reasons for a change that has occurred.

- Identify opportunities for improvement using trend and/or Pareto charting. 


\section{NOTE}

Methods selected from Attachment 2, Data Analysis Methods, and Attachment 3, Control Charts, will be used for analyzing the information unless other documented guidelines are approved by the requesting management.

5.3 Define the data that are to be collected.

5.4 Collect and analyze the appropriate data.

5.5 Identify the source(s) of the data.

5.6 Identify the specific item characteristic(s) or process/performance related information that is to be analyzed.

5.7 Perform analysis of the data, and using Attachment 2, determine if a trend exists

5.8 Consult with appropriate SME for background information on identified trends.

5.9 Document and report findings and observations to management.

\section{NOTE}

Appropriate actions may include gathering and analyzing additional data to determine the impacts of reported findings and observations or initiating corrective action in accordance with LBNL/PUB-5519 (1).

Management

5.10 Review, approve and issue Trend Report findings and observations.

5.11 Resolve any concerns with the Analyst.

5.12 Ensure that the Trend Report is disseminated to affected organizations.

5.13 Ensure that appropriate actions are taken based on the findings and observations.

5.14 If a significant trend exists, using guidance in Attachment 2 determine the special cause(s) of variation.

5.15 If the process is stable, but is in need of improvement, using guidance in Attachment 2, determine the common cause(s) of variation.

5.16 If a recurring adverse condition is identified, evaluate and analyze the condition in accordance with LBNL/PUB-5519 (1) and LBNL/PUB-5519 (2).

5.17 Modify/recommend changes to goals, targets and/or control limits as applicable. 
LBNL/PUB-5519 (3), Rev. 0

Data Monitoring and Analysis Program Manual

\section{Attachment 1 - Definitions}

\begin{tabular}{|c|c|}
\hline Analyst & $\begin{array}{l}\text { An analyst studies program or process data and recommends } \\
\text { appropriate actions to management based on that data. The analyst } \\
\text { may also serve multiple functions. For example, the analyst may also be } \\
\text { the SME of a particular program or process. }\end{array}$ \\
\hline Change & $\begin{array}{l}\text { The term "change" is used in this procedure when analyzing control and } \\
\text { runs charts to designate any instance where the charted data indicates } \\
\text { that special cause variation is present. Trends, shifts, and outliers are } \\
\text { specific types of changes. }\end{array}$ \\
\hline Chart, Control & $\begin{array}{l}\text { A control chart is produced by plotting data points, or averages of groups } \\
\text { of data points, in time sequence and adding a statistically derived } \\
\text { performance mean and control limits to the chart. A control chart allows } \\
\text { the stability of a process over time to be assessed. }\end{array}$ \\
\hline Chart, Pareto & $\begin{array}{l}\text { A Pareto chart is used to identify the primary sources of process } \\
\text { problems and opportunities for improvement. }\end{array}$ \\
\hline Chart, Runs & $\begin{array}{l}\text { A runs chart is produced by plotting data points in time sequence and } \\
\text { contains a center line, which is the mean or median. }\end{array}$ \\
\hline $\begin{array}{l}\text { Common Cause } \\
\text { Variation }\end{array}$ & $\begin{array}{l}\text { The variation inherent in a process that is in statistical control (or in other } \\
\text { words, predictable). It consists of many different individual causes, each } \\
\text { of which contributes only a small amount of variation. Examples: human } \\
\text { variation in setting control dials, slight variation in raw materials, slight } \\
\text { changes in temperature. If the observed common cause variation is not } \\
\text { acceptable, the process has to be changed. }\end{array}$ \\
\hline Control & $\begin{array}{l}\text { The term "control" is used in this procedure to maintain consistency with } \\
\text { statistical and quality control literature when referring to "statistical } \\
\text { process control," "control charts," and "control limits." In most } \\
\text { applications on site, these techniques are used to monitor performance } \\
\text { and to assess the effects of system or process changes on performance. } \\
\text { Often, the term "monitoring" may be substituted for the word "control" to } \\
\text { give a description that is more appropriate for our applications. }\end{array}$ \\
\hline Data Point & $\begin{array}{l}\text { The numeric value of a measurement at a point in time or for a time } \\
\text { period. }\end{array}$ \\
\hline
\end{tabular}




\section{Attachment 1 - Definitions}

\begin{tabular}{|c|c|}
\hline Data Sources & $\begin{array}{l}\text { External oversight activities, Nonconformance Reports (NCRs), } \\
\text { Corrective Action Reports (CARs), Findings (including those items that } \\
\text { were considered conditions adverse to quality [CAQs] which were closed } \\
\text { during the course of the QA audit or surveillance), Price Anderson } \\
\text { Amendments Act (PAAA) Noncompliance Tracking System (NTS) } \\
\text { reportable items, and Occurrence Reporting and Processing System } \\
\text { (ORPS) reportable items. }\end{array}$ \\
\hline Outlier or Freak & $\begin{array}{l}\text { For an individual data point, an abrupt change in the level of } \\
\text { performance from the historical performance mean, the performance } \\
\text { level exhibited by the preceding data points, or the trend line. Outliers } \\
\text { are usually excluded when determining shifts, performance means, } \\
\text { spreads, and trends; the remaining data points are considered to be } \\
\text { consecutive. }\end{array}$ \\
\hline $\begin{array}{l}\text { Performance } \\
\text { Mean or Average }\end{array}$ & The arithmetic average of a series of consecutive data points. \\
\hline Shall & $\begin{array}{l}\text { Identifies those elements and requirements that have been considered } \\
\text { and found to meet DOE, Contract or implementing requirements. }\end{array}$ \\
\hline Shift & $\begin{array}{l}\text { An abrupt change in performance away from the trend line or the } \\
\text { performance mean of the prior set of data points. At least two data points } \\
\text { are required to indicate a shift. }\end{array}$ \\
\hline Should & $\begin{array}{l}\text { A recommendation that is based on standards and good business } \\
\text { practice. }\end{array}$ \\
\hline $\begin{array}{l}\text { Special Cause } \\
\text { Variation }\end{array}$ & $\begin{array}{l}\text { The variation that causes a process to be unpredictable. It consists of } \\
\text { one or a few individual causes, each of which contributes a large amount } \\
\text { of variation. Examples: a faulty setup, a batch of defective raw materials, } \\
\text { a machine malfunction, use of the wrong procedure. }\end{array}$ \\
\hline Spread & $\begin{array}{l}\text { For a series of consecutive data points, using the two points (one | above } \\
\text { and one below the trend line) that are located the farthest distance away } \\
\text { from the trend line, the sum of their vertical distances to the trend line. }\end{array}$ \\
\hline $\begin{array}{l}\text { Subject Matter } \\
\text { Expert (SME) }\end{array}$ & $\begin{array}{l}\text { The functional title for the designated individual who has technical } \\
\text { expertise and knowledge in a specific programmatic area. }\end{array}$ \\
\hline
\end{tabular}


LBNL/PUB-5519 (3), Rev. 0

Data Monitoring and Analysis Program Manual

\section{Attachment 1 - Definitions}

\begin{tabular}{|c|c|}
\hline Trend & $\begin{array}{l}\text { A general inclination, tendency, direction of movement, or course that } \\
\text { indicates a statistically detectable change in performance over time or in } \\
\text { comparison with a previous time period. When used as a verb, to "trend" } \\
\text { means to perform trend analysis. }\end{array}$ \\
\hline Trend, Adverse & $\begin{array}{l}\text { An identified trend that indicates degradation in performance and has } \\
\text { major cost, schedule, safety or quality implications, and has been } \\
\text { investigated and confirmed by a program technical authority and } \\
\text { responsible management. }\end{array}$ \\
\hline Trend Analysis & $\begin{array}{l}\text { The monitoring and evaluation of performance indicators over time to } \\
\text { identify trends and other changes. This may include a determination of } \\
\text { the statistical significance of identified changes and trends. }\end{array}$ \\
\hline Trend, Favorable & $\begin{array}{l}\text { An identified trend that indicates improvement in performance and has } \\
\text { been investigated and confirmed by a program technical authority and } \\
\text { responsible management. }\end{array}$ \\
\hline Trend, Identified & $\begin{array}{l}\text { A datum point, or pattern of data points, on a runs or control chart that } \\
\text { meets one of the predetermined statistical rules for indicating a trend or } \\
\text { other change. }\end{array}$ \\
\hline Trend Line & $\begin{array}{l}\text { Normally, a straight line that depicts the overall trend of a series of } \\
\text { consecutive data points. The line can be drawn by visually minimizing } \\
\text { the vertical distances generated by more sophisticated statistical } \\
\text { procedures. The trend line can be curved, or even a series of steps, } \\
\text { when deemed appropriate by the trend analyst. }\end{array}$ \\
\hline Trending & $\begin{array}{l}\text { Analyzing data to identify major contributors to performance or lack of } \\
\text { performance during a time period or to identify changes in performance } \\
\text { over time. }\end{array}$ \\
\hline
\end{tabular}




\section{Attachment 2 - Data Analysis Methods}

\section{Keys to Improving Performance}

Work is a series of interconnected processes, and variable improvement can be attained by reducing process variation to minimize variation in a process. Its sources must be identified and reduced or eliminated. Major sources of variation include differences in personnel, location, machines, materials, and methods.

Trend charts, or runs charts or control charts, are used to identify and understand the magnitude and sources of process variation, and to predict future process performance. Understanding a process' variation (knowing if a process is stable and how much variation is inherent) facilitates one's ability to predict the range and level of future performance, and to identify and eliminate, or minimize special cause variation.

Pareto charts can be used to identify major sources of variation. There are two types of variation - common cause and special cause; the variation that can be removed from a process by identifying and controlling its sources is called "special cause"; variation | when a process is predictable, is a "common cause" variation. The work of removing special causes (fixing a process problem) is inherently different from the work of minimizing common causes (improving the whole process).

\subsection{Data Analysis}

Data analysis techniques, such as runs charts, control (or monitoring) charts, and Pareto charts, provide management with objective tools that can be used to monitor and assess progress and to support management's effort to establish a work environment that fosters an attitude and ethic of continuous improvement.

Using these data analysis techniques, programs and organizations can identify stable processes, effects of improvement efforts, opportunities for improvement, and potential problems that may seriously impact operations and/or performance. When an adverse trend or other change is identified, responsible management decides if further analysis is required to determine the meaning and impact of the indicated change and if corrective action is needed. Quantitative data cannot capture all aspects of performance. The analysis of data may indicate a problem when actually a system or process change has occurred which affects the interpretation or validity of the data.

Care must be used when reporting changes indicated by data analysis. An indicated significant change is the trigger to investigate the underlying situation to determine whether or not actual improvement or degradation of performance has occurred. 


\section{Attachment 2 - Data Analysis Methods}

\subsection{Trending}

Trending is often a loosely defined term, used to refer to methods of analyzing data to identify changes in performance or opportunities for improvement. Usually, trending refers to analyzing data in time sequence order to identify changes in performance.

\subsection{Trend Charting}

There are two basic types of trend charts; runs charts and control charts. Both runs charts and control charts are effective in identifying changes in process performance. Runs charts are easier to produce and simple to interpret. Control charts require more knowledge and special calculations to be used properly. There are many different types of control charts and different methods of calculating the performance mean and control limits.

Other types of control charts and analysis guidelines can be found in common textbooks and guidebooks on Statistical Process Control (SPC). The most important thing is to select and consistently use a valid set of analysis rules. The specific set of analysis rules is not nearly as important. Other guidelines or subsets of the guidelines contained in Attachments 4 and 5 can be adopted or developed for specific applications.

\subsection{Types of Errors}

2.2.1 Control limits are commonly drawn at 3 standard deviations $(3 \Sigma)$ from the center line because 3 standard deviations are a good balance point between two types of errors:

- When a point falls outside the control limits even though no special cause is operating (Type I or alpha)

- When a special cause is missed because the chart isn't sensitive enough to detect it (Type II or beta)

All process control is vulnerable to these two types of errors. The reason that 3 standard deviation control limits balance the risk of error is that, for normally distributed data, data points will fall inside 3 standard deviation limits $99.7 \%$ of the time when a process is in control. This reduces the number of searches that might otherwise be initiated but still makes it likely that unusual causes of variation will be detected.

\subsection{Determining Trends}

The following guidelines can be used to determine if a process is out of control or out of control but stable. 


\section{Attachment 2 - Data Analysis Methods}

The identification of trends and other process changes, such as outliers and shifts, is a subjective process. There is no absolute set of rules for identifying trends or process changes. These criteria can be used to assist in determining when data points or patterns on runs charts should be brought to management's attention. Criteria based on "statistical control limits" can also be used.

Management should make the final determination concerning whether a situation depicted on a runs chart warrants further investigation and reporting.

The following criteria assume that data points are plotted in time order, with time being on the horizontal axis. Whenever possible, at least six data points should be used to determine a performance mean, spread, or trend line.

A Shift may exist if:

- Seven points in a row are above/below the average

- Four out of Five points are one standard deviation above/below the average

A Trend may exist if:

- There is a noticeable change in the orientation (e.g. upward or downward) of the trend lines between two consecutive groups of points.

- There is a series of seven consecutive increases or decreases.

An Outlier (or Outliers) may exist if:

- One point is outside the control limits

- Two out of Three points are two standard deviations above/below average

\subsection{Determining Special Causes}

If a process is out of control or unstable, or if a process is in control or stable but there is significant variation within it, special causes of the variation must be determined. Removing special causes when they are harmful or integrating them when they are beneficial is an important part of process improvement.

Special causes are easier to deal with if they are spotted early and the data used to identify them is timely. Tracking down special causes relies heavily on people's memories of what made that occurrence different from the others and people may quickly forget any unusual circumstances that may have triggered the unusual variation. 


\section{Attachment 2 - Data Analysis Methods}

If the data identifies a trend:

- Control any damage or problems with an immediate short term fix.

- Once the short-term fix is in place, search for the cause. This may be done through formal Root Cause Analysis in accordance with LBNL/PUB-5519 (2) or personnel interview.

- Develop a corrective action that will remove a negative special cause or integrate a positive special cause into the system.

Do not:

- Change a process to accommodate a special cause

- Blame individuals

Once the special cause of variation has been removed, in order to improve the process common causes of variation must be determined.

\subsection{Determining Common Causes}

If a process is stable, but is not meeting expectations, in order to improve the process common cause variation must be determined and reduced. Determining common cause variation is more difficult than determining special cause variation because all process data must be looked at, not just what made one point or a series of points different from the others.

Common causes of variation are typically hidden within the system.

There are different ways to search for and identify common causes. The two methods most used are experimentation and stratification.

Experimentation allows a theory to be tested when little or no data is available. The "Plan-Do-Check-Act (PDCA) cycle stresses experimentation and observation in order to discover the common cause.

- In the Planning stage, the problem is recognized and analyzed and possible solutions are formulated.

- In the Doing stage, the most likely or effective solution is implemented in a test site

- In the Check stage, the results of the test solution and the original method are compared to determine if real improvements have been made.

- In the Act stage, the old method is replaced with the new method.

Stratification allows data to be separated into categories and determination of what characteristics are the same and how they are linked. This allows for the root cause of the problem to be identified. 


\section{Attachment 2 - Data Analysis Methods}

Stratification may be made easier by using Pareto charts or bar charts that can display counts of things in different categories. The cause and effect diagram may also be used to build a tree of branching characteristics, each one being stratified further and further until root causes can be reached.

\subsection{Pareto Charting}

Pareto charts are used to identify the primary sources of process problems and opportunities for improvement. Pareto charting involves classifying aspects of performance, such as causes, programmatic elements, or requirements. Pareto charting is then used to rank the contribution of each class in order to identify improvement opportunities.

In a Pareto chart, characteristics of the product or service are examined to separate the "critical few" from the "trivial many." The Pareto principle states that approximately 80 percent of most defects or problems are caused by or come from 20 percent of the causes. To identify the causes that, if corrected, could lead to the greatest improvements, the causes, defect types, classes (programmatic elements, locations, operators, shifts, batches, etc.), or requirements related to the defects are charted to depict the frequency of occurrence. A Pareto chart helps management focus attention and efforts toward fixing the truly important problems.

\subsection{Qualitative Data}

Qualitative data can be used to measure, control and improve processes, programs and performance. Qualitative data may include, but is not limited to: surveys, logbook entries, observation of processes and personnel interviews to gauge process or program knowledge and compliance. In order for qualitative data to be effectively used for performance measurement and improvement, the data collection and input must be carefully designed and the results must be readily interpretable. The results from qualitative data can identify compliance and competency issues provided the data set is analyzed properly and thoroughly and may support fact-based decision-making.

Qualitative data can be beneficial for summarizing data and reaching generalizations based on statistical projections. In order to perform data analysis on qualitative data it must be converted to quantitative data, which means that numerical values or coding must be assigned to expected responses and/or response ranges. Once the data is in numerical form, it can be manipulated numerically. 


\section{Attachment 2 - Data Analysis Methods}

When qualitative data is used to measure performance, the following must be identified:

- The content or area to be evaluated and controlled

- Data to be collected

- How data is to be organized

- Specific lines of inquiry to effectively collect the data and ensure consistency

- Expected responses and response range for each line of inquiry

- Numerical values for each expected response and/or response range. 
LBNL/PUB-5519 (3), Rev. 0

Page 18 of 22

Data Monitoring and Analysis Program Manual

\section{Attachment 3 - Control Charts}

\section{NOTE}

The Office of Contract Assurance can assist with the determination and development of the appropriate Control Chart.

The term "control" is used to maintain consistency with statistical and quality control literature concerning SPC. In production applications, SPC is used to attain "control" of processes. In most applications on-site, these techniques are used to monitor performance and to assess the effects of process changes on performance. Being "in control" does not imply that the process is acceptable. It does imply that if it is left alone, it is predictable.

The two main uses for control charts are to:

- Warn of changes. This is done by monitoring the process to determine if it is stable and predictable.

- Assess the results of intentional process changes. This is done by monitoring the process to determine how a process change affects the process output.

All control charts have a central line $(C L)$, average, or performance mean. Control charts usually have both an upper control limit (UCL) and a lower control limit (LCL). In some cases, the calculated UCL or LCL is impossible to attain and the corresponding control limit is not used. An example of this is when the number of defects is being charted and the calculated $L C L$ is a negative number.

There is an inherent variation, but it varies between predictable limits.

\section{Selecting the Chart Type}

Several different types of control charts are available to be used in different situations. The type of data being charted determines the type of control chart that should be used.

\begin{tabular}{|l|l|l|}
\hline \multicolumn{1}{|c|}{ Type of Data } & \multicolumn{1}{|c|}{ Type of Chart } & \multicolumn{1}{c|}{ Use } \\
\hline Variables & X chart & $\begin{array}{l}\text { To plot percentages, ratios, counts and other non- } \\
\text { measurement data, even when the assumptions are only } \\
\text { approximately met }\end{array}$ \\
\hline Variables & R chart & $\begin{array}{l}\text { To plot the sample ranges in order to control the } \\
\text { variability of a variable }\end{array}$ \\
\hline Variables & S chart & $\begin{array}{l}\text { To plot the sample standard deviations in order to control } \\
\text { the variability of a variable. }\end{array}$ \\
\hline Attributes & O chart & $\begin{array}{l}\text { To plot the sample means in order to control the mean } \\
\text { value of a variable }\end{array}$ \\
\hline
\end{tabular}


LBNL/PUB-5519 (3), Rev. 0

Page 19 of 22

Data Monitoring and Analysis Program Manual

Attachment 3 - Control Charts

\begin{tabular}{|l|l|l|}
\hline \multicolumn{1}{|c|}{ Type of Data } & Type of Chart & \multicolumn{1}{c|}{ Use } \\
\hline Attributes & U chart & $\begin{array}{l}\text { To plot the number of defective units if the distribution of } \\
\text { defects is rare }\end{array}$ \\
\hline Attributes & Np chart & $\begin{array}{l}\text { To plot the number of defective units if the distribution of } \\
\text { defects is not considered rare }\end{array}$ \\
\hline Attributes & P chart & To plot the percent of defective units \\
\hline
\end{tabular}

When in doubt, use the $X$ chart. $X$ charts are recommended when plotting measurement data from subgroups of size one and can be used to plot a variety of data. Consult management and/or a statistician for assistance with choosing the right control charts for an application, establishing control limits, rules, and if you need specialized charting to identify trends.

\section{Example X Chart}

The chart below is one example of the use of this generic chart. The processing times for the first 39 work packages written in 1997 have been gathered and plotted. An initial average was calculated for all 39 packages, but it revealed that the most recent seven packages in a row were above the average. This indicates a statistically significant trend, but there is not enough data to determine if a process shift has occurred. In this instance, the average was rebaselined to include only packages 1 through 32 . Packages 33 through 39 are annotated as seven months in a row above average. If packages 33 through 39 are determined to be part of a process change, a new baseline average will be calculated once a total of 25 data points (starting with Package 33) have been generated. Note that the average line is annotated with the basis for the average. The control limits were set at three standard deviations above and below the average line. Packages 1 through 32 were also used in the standard deviation calculation. The $x$-axis is annotated as being the work package number. It is assumed that this is a time sequence. The next package written will be 97-0040. With regard to cycle time graphs, only plot the cycle times for those items which have completed the cycle. Plotting items which are still within the cycle, will cause their times will be artificially low.

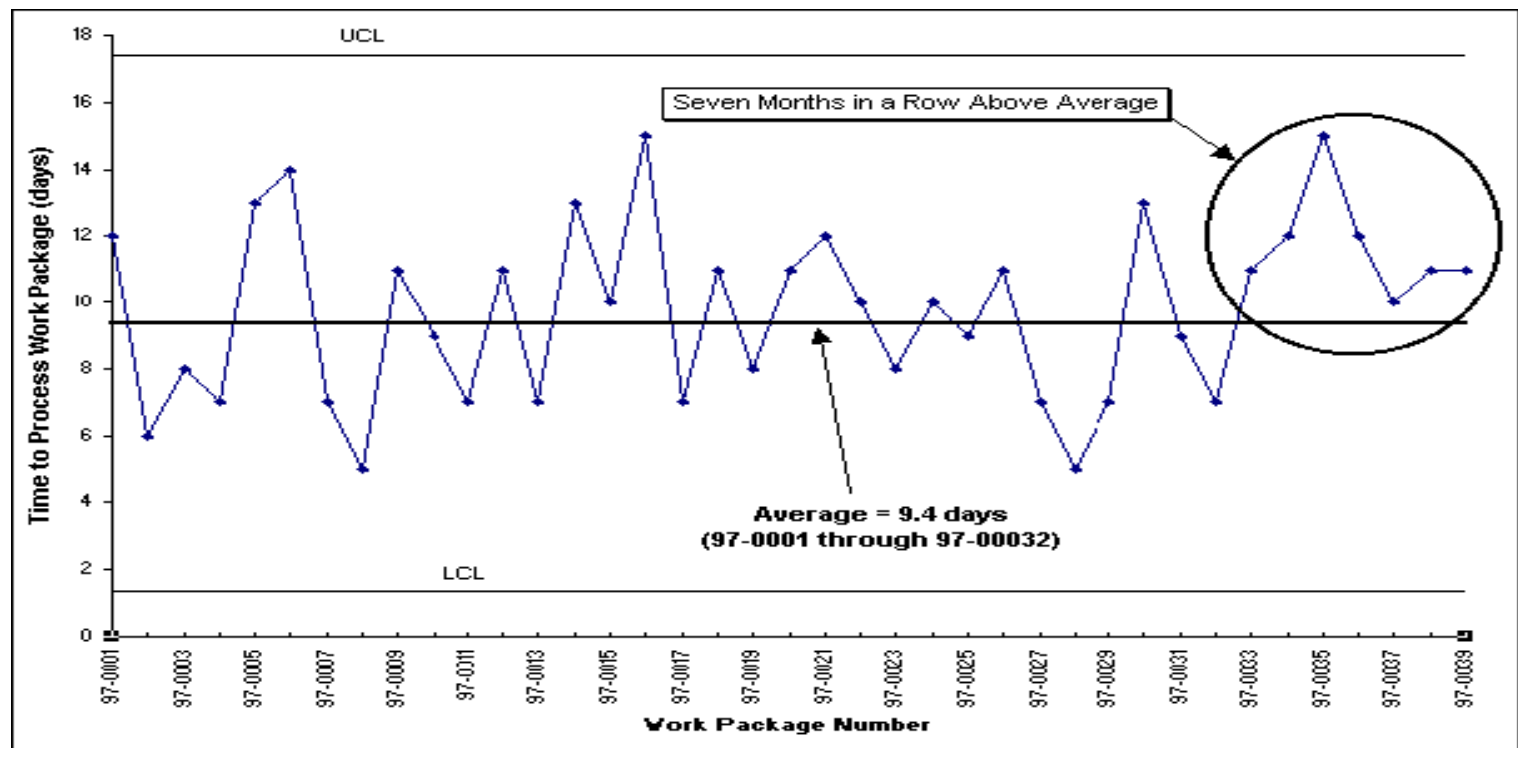




\section{Attachment 3 - Control Charts}

\section{Establishing Control Limits - Number of Data Points Needed}

One of the major problems in starting a control charting application or in modifying control limits after a change is indicated is that there are not enough data. At least 25 data points are required for determining the performance mean and control limits. This may pose a problem when each data point represents a relatively long period of time (for example, a week or a month).

Many charts are based on monthly data. Since it is desirable to start monitoring as soon as possible, first assume that the process is in control until proven otherwise. Also, assume that no improvement or degradation occurs until indicated by an "out-of-control" condition on the control chart. Then, with at least six data points, one can calculate a serviceable performance mean and estimated standard deviation.

Whenever control limits are calculated, it is appropriate to exclude from the calculations any data points that have been identified as "outliers" or "freaks."

\section{Determining when a Process Change Occurs}

One of the greatest benefits of control charting is that the charts indicate when to leave a process alone. Process modifications based on reactions to random or common cause, variation usually accomplish little more than an increase process variation because they introduce additional special cause variation to the process.

Beyond the typical one-point-beyond-3-sigma test (the "out-of-control," "outlier," or "freak" test) there are numerous tests that can be and have been statistically developed to identify process trends and other changes using control charts.

There are many ways to interpret different kinds of patterns on control charts, other than just being "out-of-control." Experience and training lead to greater skill in extracting information from control charts regarding process behavior. Questionable patterns should be reviewed by an experienced statistical analyst. In other words, the set of tests may not indicate a change, but visually, based on experience, the chart indicates that something has changed. Analysts without extensive statistical training should stick to the listed rules.

\section{Changing the Control Limits}

Data analysis is sometimes as much of an art as a science. It is difficult to give exact rules governing when to change the performance mean and/or limits. Such decisions should be based on statistical analysis, SME input, and management input.

The following should be considered when changing control limits:

- Was there a significant change to the process?

- Is the process stable?

- Is the cause of the change in the process is understood? 


\section{Attachment 3 - Control Charts}

If there is no indication of process change, the limits should be maintained "as is." Ultimately, the decision to change control limits rests with management. If one of the selected tests indicates a change has occurred, it may be time to start trying to change the limits to monitor the new situation.

Analysis of the situation by an SME to determine if the change is due to a process change, measurement change, or other identifiable special cause should be performed prior to changing the control limits. If a special cause can be identified, the new performance mean should be based on all data available. After that time the upper and lower limits should be based on the previously estimated standard deviation until six to twelve new data points are available for calculating a new estimate.

If the process has gone out of control and the objective is to have it returned to the existing control limits, no change is required. If the change is favorable, it may be desirable to change the performance mean and limits to monitor the process at the new level.

Once a process change is indicated and a decision is reached to change the limits, a new performance mean should be calculated based on the first three data points after the start of the change.

Continue to use the prior estimate of the standard deviation until at least six new data points have been collected. Once six new data points have been collected, recalculate the performance mean and control limits based on those data points. If the process remains in control, the mean and limits should be recalculated again after 12 and 24 data points become available. At that point, they should not be recalculated again until a change is indicated by the chart. 
LBNL/PUB-5519 (3), Rev. 0

Data Monitoring and Analysis Program Manual

\section{Attachment 4 - Trend Codes}

\begin{tabular}{|c|c|}
\hline $\begin{array}{l}\text { Trend Code } \\
\end{array}$ & Description \\
\hline $\begin{array}{l}\text { A. Policies/Procedures/Instructions } \\
\text { Not Used }\end{array}$ & $\begin{array}{l}\text { Use if there was a policy, procedure or other written instruction or } \\
\text { document that existed, but was not used, not adhered to, not } \\
\text { followed or intentionally followed incorrectly. }\end{array}$ \\
\hline $\begin{array}{l}\text { B. Policies/Procedures/Instructions } \\
\text { Used Incorrectly }\end{array}$ & $\begin{array}{l}\text { Use if the policy, procedure or other written instruction or } \\
\text { document was used, but made a mistake and/or did not do what } \\
\text { was intended. }\end{array}$ \\
\hline $\begin{array}{l}\text { C. Policies/Procedures/Instructions } \\
\mathrm{NI}\end{array}$ & $\begin{array}{l}\text { Use if the policy, procedure or other written instruction or } \\
\text { document lacked adequate information; contained confusing or } \\
\text { conflicting information; or if no policy, procedure or other written } \\
\text { instruction or document existed. }\end{array}$ \\
\hline D. Communication NI/LTA & $\begin{array}{l}\text { Use if there was a lack of communication, an error made during } \\
\text { communication between people performing the work or if verbal } \\
\text { communication was misunderstood or misinterpreted. }\end{array}$ \\
\hline $\begin{array}{l}\text { E. Equipment/Software Design } \\
\text { NI/LTA }\end{array}$ & $\begin{array}{l}\text { Use if the equipment and/or software code was designed in- } \\
\text { house and the difficulty was due to a design problem that caused } \\
\text { the equipment/software to fail or the integration of the two, } \\
\text { thereof. }\end{array}$ \\
\hline F. Maintenance NI/LTA & $\begin{array}{l}\text { Use if a maintenance program was developed but was not used } \\
\text { or the maintenance was inadequate. }\end{array}$ \\
\hline G. Training NI/LTA & $\begin{array}{l}\text { Use if training should have been provided but wasn't or if it was } \\
\text { inadequate to provide the necessary knowledge and skills } \\
\text { needed to successfully complete a task. }\end{array}$ \\
\hline H. Work Planning NI/LTA & $\begin{array}{l}\text { Use if there preparation for work inadequate or did not take place } \\
\text { prior to the start of work and should have. }\end{array}$ \\
\hline $\begin{array}{l}\text { I. Work Processes/Packages } \\
\text { NI/LTA }\end{array}$ & $\begin{array}{l}\text { Use if the work process or work package, including the } \\
\text { hazard/risk assessment, was inadequate; if a pre-job briefing was } \\
\text { needed but wasn't given; if resources were inadequate or not } \\
\text { available; or if schedules conflicted, etc. }\end{array}$ \\
\hline $\begin{array}{l}\text { J. Material/Equipment/Software } \\
\text { Deficiency }\end{array}$ & $\begin{array}{l}\text { Use if material/equipment/software was defective prior to use; } \\
\text { proven to be defective because of improper manufacturing, } \\
\text { procurement, handling/shipping/ storage/receipt; or inappropriate } \\
\text { for the system }\end{array}$ \\
\hline K. Vendor Deficiency & $\begin{array}{l}\text { Use if a vendor's procurement program was determined to be } \\
\text { deficient or inadequate. }\end{array}$ \\
\hline L. Data/Information NI/LTA & $\begin{array}{l}\text { Use if data or information used to perform work or make } \\
\text { decisions was inaccurate, not available within a timely manner, or } \\
\text { non-existent. }\end{array}$ \\
\hline $\begin{array}{l}\text { M. Technical Proficiency } \\
\text { Deficiency }\end{array}$ & $\begin{array}{l}\text { Use if personnel or team selection was determined to be } \\
\text { incorrect or inadequate. }\end{array}$ \\
\hline $\begin{array}{l}\text { N. Process/Task Design } \\
\text { Deficiency }\end{array}$ & $\begin{array}{l}\text { Use if the design, or a portion thereof, of a process or task was } \\
\text { deficient prior to being used. }\end{array}$ \\
\hline
\end{tabular}

*Only one trend code per issue may be used. 